\title{
THE EXPERT WITNESS IN CHILD ABUSE AND NEGLECT: AN INTERDISCIPLINARY PROCESS
}

\author{
DONALD N. DUQUETTE, J.D. \\ University of Michigan, 1015 E. Huron, Ann Arbor, Michigan 48109
}

\begin{abstract}
The legal system is an important part of a society's response to child abuse and child neglect. Courts need to be guided in their deliberations by experts from many different professions. Consultation and in-court expert testimony is necessary from medicine, psychology, psychiatry, social work and other professions both to prove child abuse and neglect and establish the power of the court to act on behalf of a child but also to guide the court in the intervention strategy most suited to the needs of the child and his family. Non-lawyers often feel uncomfortable in the legal setting. The adversary process is foreign to their training and professional experience. Collaboration with a lawyer greatly improves their effectiveness in court. Lawyers, on the other hand, need to make maximum use of medical and social-psychological experts in the court process in the interests of their clients; but to do so lawyers need a basic understanding of the other professions. With an emphasis on a process of mutual education, the paper presents a framework for collaboration between lawyers and expert witnesses in child abuse and neglect cases. "Expert witness" is defined; informal consultation is encouraged; suggestions for selecting a collaborator are made; initial contracts between lawyer and expert, case conferencing and preparation for trial are discussed; specific advice on direct and cross examination is provided.
\end{abstract}

Key Words - Child abuse; Law; Testifying; Interdisciplinary collaboration; Expert witness.

Résumé—Cet article, écrit par un juriste, a pour but de guider les juristes impliqués dans des cas de maltraitance d'enfant. Les tribunaux ont besoin de témoignages d'experts, appartenant à des professions très diverses: médecins, psychologues, psychiatres, travailleurs sociaux. Les personnes non-juristes se sentent en général mal à l'aise dans le cadre de la justice. Le processus dit "adverse" leur est étranger. S'ils collaborent avec un avocat, ils deviennent beaucoup plus efficaces. Cependant les avocats et les juristes ont aussi besoin des lumières des autres professions, et doivent avoir une certaine compréhension de ce que font les autres professions. Cet article offre des directives à l'usage des juristes et des experts qui doivent têmoigner en justice en cas d'affaire de maltraitance d'enfant.

\section{INTRODUCTION}

THE FOLLOWING is provided as a framework for lawyers and their expert witnesses in child abuse and neglect cases. The collaborative process between courts and the medical and mental health professions is central to development and maintenance of a system which has as its primary goal the rehabilitation of families rather than punishment. The parens patriae philosophy and history of juvenile and family courts in the United States encourages reliance on experts to develop the kind of information and direction in the legal process that increases awareness and understanding of the social-psychological forces behind child abuse and child neglect. What society does in response to inadequate parenting, sometimes manifested as child abuse, is as important a question

Donald N. Duquette, B.A., J.D., is Clinical Associate Professor of Law, Director of the Child Advocacy Law Clinic at the University of Michigan, and Co-Director of the University of Michigan Interdisciplinary Project on Child Abuse and Neglect.

Evolution of ideas in a clinical setting is also an interdisciplinary process. The ideas expressed in this paper reflect nearly four years of experience with various members of the Interdisciplinary Project on Child Abuse and Neglect but particularly with Ann Thompson, M.D., a child psychiatrist. Dr. Thompson and the author have worked together on many cases and presented seminars and public talks on the subject. This paper could not have been written without Dr. Thompson's collaboration. 
as establishing the legal jurisdiction to act. Unless we act wisely, the child affected may be as traumatized by the process of state intervention as by the initial abuse or neglect.

Experts from other disciplines guide the court at all phases of the legal process. Effective use of their talent depends on an interdisciplinary process in which lawyers are educated about what the other disciplines have to offer the legal process and in which the other professions are made familiar with the workings of the court. Counsel opposing medical or mental health expert testimony is better equipped to test their conclusions on cross-examination if he or she understands the basics of that profession and, better yet, has occasional access to an expert as the cross-examination is prepared.

The following will discuss: (1) Who is considered an "expert" witness; (2) Informal consultation between professions; (3) Selecting the expert, selecting the lawyer with whom to work; (4) The initial contract between the lawyer and an expert; (5) The important case conference between lawyer and expert in which a process of mutual education occurs; (6) The mutual decision to continue collaboration into negotiation and trial; (7) Preparation for direct examination and crossexamination. Experts are called to consult and to testify by all three parties in child protection cases - by the state agency, by the child and by the parents. The following has all three parties in mind.

\section{WHO IS CONSIDERED AN "EXPERT WITNESS”}

An expert witness is a person qualified by training and experience in scientific, technical or other specialized knowledge to assist the trier of fact (the judge, or the jury if there is one) to understand the evidence or to determine a fact in issue. A witness qualified as an expert can testify in the form of an opinion [1]. In practice, lay witnesses (i.e., nonexperts) generally cannot testify as to their opinion [2].

The trial judge in most United States jurisdictions has broad discretion in accepting or not accepting a witness as an expert. Therefore, who is accepted as an expert may vary somewhat from place to place and from judge to judge. The law of expert testimony can be complex and varies somewhat from jurisdiction to jurisdiction. As a practical matter the decision to accept a witness as an expert or not in child abuse and neglect cases seems to turn on two important factors: his or her education and the length and type of his or her experience.

The scope of a witness' expertise is limited by his/her professional training and experience. For example, a psychologist will generally not be permitted to give his or her opinion on whether or not physical injuries were accidentally or nonaccidentally caused. A good cross-examiner will generally try to limit the scope of the witness' expertise.

\section{INFORMAL CONSULTATION ENCOURAGED}

Experts need not be used only for testimony in court. For example, a parents' or child's attorney may need consultation on dealing with his client, on determining the best interests of his client, on fashioning a treatment plan, on what can reasonably be expected of the mental health agency or the social service agency. Such collaboration with other professionals, as part of the lawyer's advocacy but apart from the needs of direct and cross-examination at trial, are encouraged.

One need not think of expert consultation as exclusively a formal matter. Take a doctor, or psychologist, or lawyer to lunch. Get to know the other person's territory. The informal contacts may reveal ways in which the other disciplines may be helpful; ways that were never apparent before. Every lawyer who has worked in child abuse and neglect has had conversations with social workers. Be the conversations long, short; bitter or sweet, the lawyer should come away with a better understanding of what the social agency is all about and vice versa. 
Developing an informal network across professional lines with a shared interest in children and families facilitates consultation which may be formal, i.e., for a fee or on a particular case; or informal, say a phone call: "Hello Susanne, let me tell you about what a psychiatrist said on this case of mine. Please tell me if it seems reasonable to you."

Effective consultation across discipline lines depends first of all on recognizing the need, i.e., recognizing what the other profession can do for you. The lawyer needs to be acquainted with issues of child development, medicine, decisions on separating parent and child, and what to expect of social agencies in child abuse and neglect cases. In an area of the law that depends so heavily on behavioral science and medicine the lawyer must know enough about the other disciplines so that he can ask questions of them, learn from them, and challenge them when appropriate.

Certain criteria can be identified to guide the lawyer or non-lawyer in selection of a collaborator, where either has a choice. Let's begin with what a lawyer should consider in selecting an expert The lawyer needs to be able to rely on his expert's skill and judgment and must also feel comfortable in a working relationship with him or her. Development of an informal interdisciplinary network as described above is an ideal way to identify potential experts. A mental health acquaintance may recommend someone as especially skilled. A university connection may either provide or recommend someone.

An attorney may rely upon a community council on child abuse and neglect or on a working child protection team in a local hospital. Make contact and ask for a reference to a physician, psychiatrist, psychologist or social worker who may provide the needed consultation. Under certain circumstances it may be appropriate to get a recommendation from a juvenile or family court judge. Recommendations from others who know the expert's work is an important barometer for the lawyer since he or she is not in a good position to evaluate the professional's expertise without outside advise.

The lawyer should assess how clearly the prospective expert witness expresses him/herself on technical matters. Does he or she use excessive amounts of jargon or is he or she able to communicate to the layman in the "King's English"? Is the prospective consultant willing and able to teach the lawyer the basics of his/her science to help the lawyer understand and appreciate the expert's point of view. The lawyer's ability to present the expert testimony clearly and persuasively in court turns on how well he or she understands what the expert has to say.

Essentially the lawyer wants someone who knows the subject well, is respected in the professional community, has some status in that community, is articulate and is willing to assist the lawyer in presenting the information to the greatest advantage.

What should a non-lawyer consider in agreeing to work with a particular lawyer? The potential expert should look at the attorney's skill and reputation as a lawyer, at his/her ability to communicate the law and workings of the legal process to the expert, and his/her willingness and ability to learn about the expert's field.

An assessment of an attorney can be done analogously to an attorney's assessment of the expert. Rely on an informal network, if you have one. Talk to people who have worked with this particular attorney as expert witnesses or in other settings. Ask other attorneys in your community about his/ her reputation. Does the potential expert feel personally comfortable in a working relationship with this particular lawyer?

How is the lawyer as teacher? The lawyer should describe fairly clearly to the expert the legal context in which the particular problem presents itself. The lawyer, too, should avoid jargon. He or she should be willing and able to teach the expert about the court process - about direct examination and about cross-examination - and should be ready to spend sufficient time with the expert to both learn about the expert's field and to prepare the expert for court testimony.

Is the lawyer willing and able to learn about the expert's profession? Is the lawyer flexible enough to learn from the expert and perhaps to change his behavior and tactics in the legal process (within the limits of his advocate role, of course) based on the expert advise? For example, to 
make maximum use of a psychiatrist as witness the lawyer not only needs some basic knowledge of psychiatry but also needs to have sufficient respect for the profession so that he or she is motivated to learn all he or she can. Some attorneys summarily discount psychiatry as having little useful to contribute. A healthy skepticism and awareness of limits is one thing, many psychiatrists have that. A closed mind to what the profession has to offer is something quite different and should be avoided.

Some attorneys just cannot think psychologically. As bright as they might be and even willing to listen, they cannot hear and understand what the mental health professional is trying to say. The potential expert is well advised to determine if the lawyer is "trainable" in their science. The lawyer need not become a physician, mental health professional or social worker, but he must understand the professions and the basics of the subject matter well enough to make good use of the experts in the legal system.

\section{THE INITIAL CONTRACT}

The first contact between the potential expert and the lawyer may be in person but more likely will be by phone. The lawyer should describe the facts and the legal context of the case and the legal question which the expert may be able to address. For example, among questions put to the expert may be: Were the injuries inflicted? Is there a reasonable expectation that the parent will be able to assume care and custody of the child within a reasonable length of time considering the age of the child? Generally the lawyer asks the expert for a preliminary assessment of the case.

Certain logistics should be settled initially. When is the trial date? What examinations, if any, does the expert consider necessary before a prelininary assessment of the case is possible? When should the lawyer and expert meet for their case conference [3].

An agreement should be entered into between the lawyer and the expert at this point. The agreement should include a promise by the lawyer to present the legal context and questions to the expert. That may be done over the phone in some cases, but most cases will require a brief written statement in a letter to the expert. That letter can be the same one which confirms the initial agreement. The lawyer should also agree to provide whatever records and other materials are necessary for the expert's preliminary assessment of the case.

The expert should agree to do an initial assessment of the case based on the records or on some additional examination of the parents and/or children. The expert may already have firsthand information about the case and fecl that no additional information is necessary.

The lawyer should defer to the expert's judgment about what sort of preliminary assessment is required. For example, the psychiatrist, better than the lawyer, will know whether one, two or no family interviews is necessary to form a preliminary assessment. The lawyer may have to set monetary or time limitations, however. "Dr. Freud, I need an assessment about whether or not my client has the potential to resume care and custody of her child within the near future and what should be done to help her realize that potential. We can afford only four hours of your time before the trial. Can you give us preliminary assessment within two hours so we still have two hours at least to prepare for trial?" Dr. Freud is the best person to decide whether he or she can work within those limits and how best to use the available time. Lawyers and judges have been known to request "psychologicals" of a parent which to many mental health professionals means only testing, when the real need was for an expert evaluation of the parent and the parent and child together, which may or may not include psychological testing. Put the question to the expert in terms of outcome data desired; let the expert use their professional judgment as to how to get that information.

The first phone contact with the expert ought to cover the matter of fees. Whether the funds come from public or private sources the expert should understand and agree to the fee schedule. 
The initial agreement should generally not include court testimony, unless the expert already knows the case, say from firsthand experience in the hospital. The initial agreement should go only so far as an initial assessment of the case resulting in fairly firm conclusions about how the clinical data relates to the legal questions put by counsel [4].

Both the lawyer and the expert retain the option of not collaborating at trial if the expert's assessment of the clinical data will not be useful at trial. All lawyers, however, will want an understanding that the expert fully expects to testify if at their case conference they determine testimony is appropriate. Some experts are willing to do an assessment of the case, as long as they are not called to testify in court. Such consultations are of very limited utility to the lawyer.

At an evaluation of a family the expert should be clear what privacy or confidentiality the examinees can expect. For example, a psychologist might say: "the material will be shared with your attorney and perhaps with the court," or "the exam is for court purposes and the results will be shared with the court."

Upon completion of the expert's preliminary review of the case the expert reports back to the lawyer with tentative responses to the legal questions. The subsequent meeting between the lawyer and the expert presents a decision point at which they either can terminate their relationship or proceed together through negotiations and, perhaps, trial.

\section{CASE CONFERENCE BETWEEN LAWYER AND EXPERT}

The business of the case conference between the lawyer and the expert, following the expert's preliminary review of the case includes the following:

1. Expert reports findings and interpretations of those findings to lawyer;

2. Expert and lawyer decide whether they will continue collaborating on the case, and if so;

3. How may the expert's findings and opinions be best presented to the court or best used in negotiation;

4. Expert and lawyer continue the process of mutual education.

The expert should begin the conference with a response to the lawyer's previously asked questions. As the data of the expert is laid out the lawyer may ask clarifying questions both about the data and its primary sources with an eye toward rules of evidence, but also about the expert's theory and professional judgments. For example, a lawyer may have consulted a child psychiatrist on the question of a very young child's physical and emotional needs and the ability of a chronically mentally ill mother to provide them. The expert would have to describe not only the factual data but also the child development theories of attachment, and separation and theories explaining the mother's condition. While the lawyer need not become a trained psychiatrist, he or she should understand the theories sufficiently to follow the expert's reasoning facilely. The greater the attorney's familiarity with the expert's data and theory the better he or she can assess the expert as witness and the more effective he or she can present the testimony in court.

Following a report of the expert's findings, the expert and lawyer must decide whether they wish to continue their collaboration. The lawyer must consider as his central question whether or not the information derived from this expert will have utility in his case as advocate for a particular party. For example, a lawyer for parents may have sought consultation from a private social worker on a treatment plan proposed by the public agency. The lawyer may have been looking for treatment alternatives that put the children back into the home sooner. The social worker consultant's independent conclusions may support the public agency and urge continued out-of-home placement. The parents' lawyer will probably not call his expert social worker to testify on disposition. He may use the independent consultation in counseling with his clients, however.

The decision to continue collaboration to trial or not should be a mutual one. Either the expert 
or the lawyer can decide not to proceed. For example, a psychologist asked to examine a mother and three children by the mother's attomey found strengths in that relationship unreported by the public agency social worker. He was also critical about the sporadic, inconsistent social services provided the mother and the prolonged foster placement of the children. However, the psychologist concluded that the children needed certain special services before they should be returned to their mother's care. The psychologist should be satisfied that his testimony in court will allow him to present his full and fair conclusions. He should be able to present material critical of the social agency handling of the case but also the material which may support their recommendation.

Once the decision is reached that the lawyer-expert collaboration will continue to the trial or in the settlement negotiations, then attention should be turned to how the case may best be presented. Expert opinion very often stands at the peak of the pyramid, that is it relies on material facts which must be put into evidence before the expert testifies. The lawyer and the expert together must determine what factual data are necessary to support the expert's opinion. A social work expert may need considerable history and proof of certain incidents to support his/her testimony. A pediatrician may only need a properly admitted medical record. A mental health expert may need records, history and proof of various incidents.

Having established what factual basis is necessary for the expert to testify the pair must turn to preparation of the expert's own testimony.

\section{PREPARING TO TESTIFY IN COURT}

Even the most expert testimony is more persuasive and the most effective if the conclusions, opinions and recommendations are based on a solid foundation of facts - on the primary data. Factual data is the comerstone of the legal process. The judge first needs to know who did what, where, when, to whom? The judge needs to hear about concrete specific observations of firsthand witnesses. What did the witness see, taste, hear, smell, touch that is relevant to the court's inquiry.

Experts with firsthand observations of the child or the family or the environment are generally more persuasive to the court. Such witnesses describe what they personally observed and then draw inferences from their own experiences. Firsthand knowledge of a case by an expert is not a technical requirement [5]. Firsthand knowledge simply strengthens the expert's persuasiveness to the court.

The factual basis for the primary data behind an expert's testimony should be established either by the expert or by previous witnesses. The expert is then able to draw inferences from the data and by his or her reasoning connect the observed factual data to his or her opinions and conclusions.

The importance of the step-by-step reasoning which connects the primary data and the expert's conclusions should be emphasized. The judge will not be as persuaded by a witness who says, "I am an expert, this is my conclusion, trust me"; as by the witness who leads the judge through the primary data, the reasoning and then to the conclusions.

Much of the lawyer-expert collaboration described above involves the expert educating the lawyer about his or her discipline and reporting to the lawyer how the discipline can cast light on the legal questions presented. At the final stage of the collaboration the lawyer becomes the teacher and begins to tutor his witness in the art of testifying clearly and effectively in court.

Many potential experts with exceptional skill in their field will be anxious about the court process and their performance as witness. "What will happen on cross-examination? I know those lawyers will make a fool out of me." The lawyer is well advised to deal with the expert's anxiety early on by giving some words of encouragement and some specific helpful advise about the court experience.

Lawyers regularly prepare witnesses to testify. No attempt will be made here to explore exhaustively the range of techniques a lawyer might use. The potential expert witness, however, 
may benefit from some general description of the witnessing process and what to expect of direct and cross-examination.

The preparation will generally be an important part of the case conference between the attorney and expert. After learning all he or she can from the expert, the lawyer will begin considering questions to be asked at trial. The attorney needs fairly direct and simple conclusions from the expert. The expert should remember that his testimony is not like talking to his or her mental health or medical colleagues, but is more like addressing a layman. Keep it as direct and as simple as possible, while still being accurate.

The expert should participate actively in the refinement of his conclusions for testimony. Be sure the lawyer understands the limits of what the expert can say in light of the data in the case.

The attorney will draft questions to be asked of the expert at trial. It is good practice to review and refine the questions with the witness shortly before the trial. At the case conference the lawyer will also give some general advice about the court appearance. What is the judge like? What can be expected of the opposing counsel? What happens on direct examination? On cross-examination? Preparation of the case, including preparation of the witness is $80 \%$ of the task for the lawyer. If the preparation is well done, the trial should turn up no surprises.

\section{TESTIFYING}

\section{The Order of Witness Examination}

When the expert witness is called to testify he or she will be sworn in by the judge or the judge's clerk, and will then be seated in the witness stand. The order of examining witnesses is as follows:

1. Direct Examination-In a question and answer format the witness' testimony is elicited by the attorney who called him or her.

2. Cross-Examination - Other counsel have an opportunity to cross-examine the opposing witness.

3. Re-Direct Examination-At the conclusion of cross examination the attorney who called the witness has an opportunity to ask additional questions.

4. Re-Cross-Examination-Other counsel have an opportunity to ask additional questions of the witness.

5. Questions by the Judge-Finally the judge may ask questions of the witness.

6. The witness leaves the stand when excused by the judge.

\section{Direct Examination}

There is no ready formula for presenting a case in court. The goal is to be clear and logical and brief; to be persuasive to the expert's final opinion. The testimony should be fairly clear to a layman, which is what the judge generally is where the testimony includes technical and scientific matters. The testimony may be clearer if it follows the expert's usual train of thought. In direct examination of a medical witness, for instance, it is more effective to elicit medical information in the traditional medical sequence (history, examination, laboratory studies, diagnosis) because the physician tends to organize medical information that way and it helps the judge (and jury) to follow the physician's thinking more clearly.

In direct examination the witness ought to be the star. The lawyer asks the facilitating questions, but he or she wants all eyes and ears on his witness. By the lawyer's every word and gesture he 
or she reinforces the message "this person is tops; I am hanging on every word, so should you." On direct the lawyer cannot ask questions which suggest the answer. The questions should facilitate the expert's exposition of his data and his conclusions.

Direct examination is generally structured as follows:

1. Introduction and Qualification.

2. Foundation; Presentation of Facts.

3. Interpretation of Factual Data; Development of Theory.

4. Conclusions; Recommendations.

Even though the lawyer is asking the questions, it is the judge (or jury if there is one) to whom the expert should be speaking. The judge (or jury) is the fact-finder who is to be persuaded. A good practice for the witness is to make eye contact with the judge; keep in mind who the principal listener is. Courtroom seating arrangements often make regular eye contact with the judge difficult. Some judges may even make it difficult to address them because of their posture at the bench. In spite of such obstacles, the witness should remember that the judge (or the jury where there is one) is the person(s) to whom he or she should be speaking and the person(s) to whom his or her testimony should be made clear and persuasive.

The expert's testimony will inevitably be interrupted by objections from opposing counsel on a variety of legal grounds. Most objections are based on an alleged failure to comply with the rules of evidence. The judge will allow the objecting attorney to state the objection and the grounds for it; will then hear argument from the attorney objected against; and then will rule on the objection. The trial will then proceed. If a question asked of the witness has been objected to, the judge will address the witness ("you may answer the question") or may direct the lawyer to withdraw the question or rephrase it. The challenge for the witness is to maintain his or her concentration on the testimony and help the judge follow the testimony.

Speak slowly and clearly. Take your time answering a question. Don't let yourself be rushed. Be truthful and as accurate as possible.

Many expert witnesses do not fully understand the nature of opinion testimony. When the lawyer asks for the expert's opinion he is asking for his or her personal conviction and for a clinical judgment. Do not confuse opinion testimony with absolute certainty or scientific accuracy. Since scientists are well aware of the limitations of their views they may present their testimony in a hesitant, conditional and waffling way. This reflects more of the confusion about what opinion evidence is than it does about their personal commitment and convictions about their observational data and the inferences they have drawn from them [6]. When the expert is able to resolve personal doubts and come to reasonable professional opinion, that opinion, by itself, has important evidentiary value to the court. The witness may present the considerations for and against his final view but should then come to a conclusion with the reasoning which supports it. The questioning process is built into the system, the expert need not adjust for it.

\section{Cross-Examination}

In cross-examination the attorney wants to weaken or discredit the weight of the witness' testimony. The attorney's probing should not be taken personally. Harsh, cutting attacks on witnesses are quite rare, especially in the juvenile or family court. Not only are purely personal attacks on a witness prohibited by the lawyers' Canon of Ethics but it is not very persuasive either. Judges exercise a restraining influence in their courts and wish to maintain a proper decorum. The judge is charged with protecting a witness from harrassment or undue embarrassment.

On cross-examination the attorney wants to control the dialogue. Unlike direct examination, he or she can use leading questions. A favorite technique is to use close-ended questions which can be answered yes or no. "Isn't it true..." "Is it fair to say that..." On cross-examination the 
attorney wants to make himself the star, the focus of attention in the courtroom, with the witness assenting to the lawyer's propositions. Another favorite technique is lulling the witness into a pattern of assent, of acquisence, by a series of non-controversial questions which can be easily answered "yes." The witness should listen carefully to each question and respond fully if a yes or no is not accurate.

The best cross-examination is generally short and with limited goals. With great frequency the cross examiners give expert witnesses the opportunity to reiterate his or her conclusions. The witness should seize whatever chance is given to restate and clarify his or her position.

Be sure you understand the question before attempting to answer it. Ask the lawyer to repeat the question if necessary. Rephrase the question and repeat it back to the lawyer if you are not sure of it. Especially on cross-examination the attorney may set a brisk pace of question answering. The witness is well advised to pause briefly before answering each question. An attorney may ask compound questions, i.e., more than one question at a time. Pick the question apart. "Mr. Able you have asked me two questions there. Now your first question is.... My answer is...."

Pause briefly before answering each question. Collect your thoughts. Your answers should be as brief as possible while still being accurate.

Here are a few common cross-examination gambits for which the expert should be prepared.

1. The attorney may quote from books, journals or treatises. Before the books, etc., may be accepted as evidence an expert must acknowledge them as reliable authority. The witness may ask the lawyer to read specific passages to him before responding. The witness need not feel obligated to have read everything. A good answer is: "I read a great deal; very much is written on the subject...."

2. The attorney may provoke anger or defensiveness. The expert should stay cool and personally detached. He or she need not be omniscient. Ask for a recess perhaps.

3. The attorney may use agency procedure manuals. This is an effective cross-examination technique especially if the agency has not complied with its own policy. The agency persons should know and follow the mandated agency policies.

4. The attorney may use the tag line, "Isn't it possible that...." A possible response is, "It's not likely. Anything is possible, but..."

Cross-examination has many aspects of a debate, a contest between witness and lawyer. If the expert witness can be made comfortable with the legal setting, he or she has the upper hand. The lawyer will be quizzing the witness in the expert's area of expertise. Unless the lawyer is exceptionally well prepared the expert witness has the advantage.

Remember several central points on cross:

1. Reiterate and support your central conclusions whenever possible. "Like I said on direct examination...."

2. Strive to be clear and consistent in spite of the cross-examiner's attempt to complicate, confuse and cast doubt.

3. Stay cool, thoughtful and firm in your conclusions.

If the witness can be made at ease in the court setting and familiar with the legal context and is well prepared, he or she may even find the experience challenging and intellectually stimulating.

\section{NOTES AND REFERENCES}

1. Federal Rules of Evidence, Rule 701 reads: "If scientific technical or other specialized knowledge will assist the trier of fact to understand the evidence or to determine a fact in issue, a witness qualified as an expert by knowledge, skill, experience, training or education may testify thereto in the form of an opinion or otherwise."

2. Federal Rules of Evidence. Rule 701 and Advisory Committee Note. 
3. WATSON, On the preparation and use of psychiatric expert testimony: Some suggestions in an ongoing controversy. The Bulletin of the American Academy of Psychiatry and the Law 6 (2) (1978).

4. Ibid.

5. Federal Rules of Evidence, Rule 703.

6. WATSON, op. cit. 